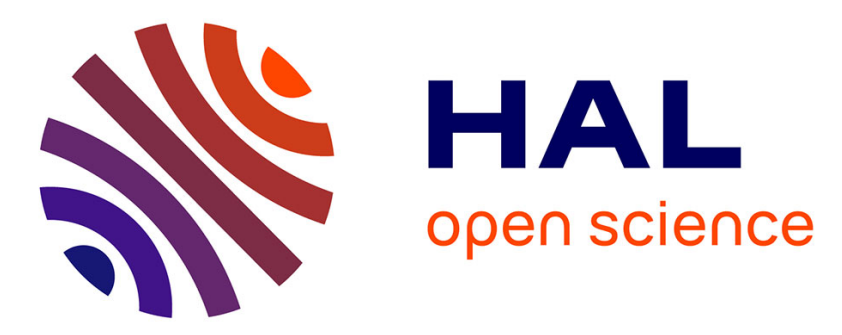

\title{
Study on Cloud Service Mode of Digital Libraries Based on Sharing Alliance
}

\author{
Xiaorong Yang, Dan Wang, Lihua Jiang, Jian Ma, Hui Xie
}

\section{To cite this version:}

Xiaorong Yang, Dan Wang, Lihua Jiang, Jian Ma, Hui Xie. Study on Cloud Service Mode of Digital Libraries Based on Sharing Alliance. 8th International Conference on Computer and Computing Technologies in Agriculture (CCTA), Sep 2014, Beijing, China. pp.404-410, 10.1007/978-3-319-196206_45. hal-01420313

\section{HAL Id: hal-01420313 \\ https://hal.inria.fr/hal-01420313}

Submitted on 20 Dec 2016

HAL is a multi-disciplinary open access archive for the deposit and dissemination of scientific research documents, whether they are published or not. The documents may come from teaching and research institutions in France or abroad, or from public or private research centers.
L'archive ouverte pluridisciplinaire HAL, est destinée au dépôt et à la diffusion de documents scientifiques de niveau recherche, publiés ou non, émanant des établissements d'enseignement et de recherche français ou étrangers, des laboratoires publics ou privés. 


\title{
Study on Cloud Service Mode of Digital Libraries based on Sharing Alliance
}

\author{
Xiaorong Yang ${ }^{1, *}$, Dan Wang ${ }^{1, *}$, Lihua Jiang $^{1, *}$, Jian Ma ${ }^{1,{ }^{*}}$, Hui Xie ${ }^{1, *}$ \\ (1. Agriculture Information Institute, Chinese Academy of Agriculture sciences, Beijing, \\ P. R. China \\ *Key Laboratory of Agricultural Information Service Technology (2006-2010), Ministry of \\ Agriculture, The People's Republic of China
}

\begin{abstract}
As a new service model, cloud services have become the growth point of the service innovation of digital libraries. By analyzing and summarizing the cloud service mode of the digital libraries at home and abroad, this paper presents three-layer cloud service model of digital libraries which includes data layer, automated management layer and service layer from bottom to top. Based on this model, this paper puts forward the union mechanism established by some libraries which joint provide intelligence research service, knowledge push service, reference service and so on.
\end{abstract}

Keywords: Cloud services, Digital library, Service mode, Sharing alliance

\section{O Introduction}

With the development of cloud computing technology, the cloud service application research becomes a hot issue. The operating mode and technical architecture of cloud service are closely related to Google and Amazon. Google put forward a complete set of distributed parallel cluster infrastructure according to the characteristics of the large scale network data. And Google provides a series of SaaS for individual users and enterprises including the Google search engine, Google maps, photos and videos sharing, social networks, Gmail, Google calendar, Google Apps Market place and so on. In order to make full use of idle IT infrastructure, Amazon provided storage servers, bandwidth and CPU resource to the third party by Amazon Web Services in 2002. In 2006, the network service platform based on cloud computing were provided 
to enterprises so that they do not need to undertake the underlying work such as hardware maintenance and can focus on their own business.

Information industry is always an important field of information technology application. To apply cloud computing technology, a library can make full use of its resources and technical strength. The service efficiency can be enhanced obviously by innovating service mode.

\section{Cloud Service Status of Domestic and Abroad Libraries}

\subsection{Cloud Service Application Research Status of Abroad Libraries}

Online Computer Library Center (OCLC) is a profitable and the largest library cooperation organization all over the world. In 2009, OCLC launched the WorldCat Local based on cloud computing technology which provides a full set of cloud computing information management service for libraries such as WorldCat.org, WorldCatLocal, Questionpoint, CONTENTdm and so on. As a library OCLC firstly applied the cloud computing technology to provide services for users.

National Digital Information Infrastructure and Preservation Program (NDIIPP) is a joint action of digital resources preservation initiated by the American Congress. In 2009, NDIIPP and Duraspaces company started the experimental project-DuraCloud together. DuraCloud provided permanent access for digital resources of back issues in the New York Public Library so as to detect the effect of cloud computing technology applied in permanent access of digital resources. This research played an important role in testing cloud computing technology applied in digital Library ( Yingjun Lu et .al, 2012).

\subsection{Cloud Service Application Research Status of Domestic Libraries}

China Academic Library\&Information System (CALIS) is a literature guarantee system for colleges and universities launched by The Ministry of Education in 1998. CALIS joined nearly 800 university libraries to provide cloud service including $\mathrm{E}$ read, current contents of western journals $(\mathrm{CCC})$, unified authentication system (UAS), 
interlibrary loan (ILL), distributed collaborative virtual reference system (CVRS) and the unified data exchange system (UES) (Wenqing Wang et .al, 2009) .

Jilin Province set up the union library which Included 50 public libraries, University libraries and scientific libraries. The union library started to plan and construct a cloud computing service platform in 2010. The platform provided IaaS for member libraries, PaaS for social users and integrated the resources of member libraries to provide unified services as SaaS.

National Science and Technology Digital Library (NSTL) is a virtual institution of science \& technology literature information service. The institution involves in science, engineering, agriculture and medicine. And it includes 9 member libraries and 50 service stations all over the country. At present the co-construction and sharing among several member libraries is SaaS. And the standard open interface service oriented group users is DaaS. In 2012, the project was started to study the cloud service mode and build the cloud service platform (Xiaodong Qiao et .al, 2010).

\section{Cloud Service Demand Analysis of Digital Libraries}

\subsection{Service Situation and Problems of Digital Libraries}

Due to the monopoly service of domestic companies such as CNKI, WANFANG and VIP in the Chinese literature resources, most of the libraries are not engaged in the electronic processing and network services of Chinese journals, dissertations, conference papers and so on. For readers, only buyers can access to these commercial database of Chinese literature resources such as CNKI. Many researchers have no effective way to obtain the required Chinese document information resources. In the processing and services of foreign literature resources, only CALIS and NSTL established the co-construction and sharing mechanism. It is common in provincial libraries and county libraries that resources are not complete and the service effects are unsatisfactory. 
Besides, the functions of cataloguing system and data processing system are unsatisfactory in some libraries because of limited capital and technical strength. When processing literature data, data format conversion between different software results to inefficient data processing work.

\subsection{Cloud Service Demand of Digital Libraries}

Cloud service pattern will bring the library more flexible, rich and diversified service changes. For libraries, to innovating the service mode based on a cloud service alliance has become inevitable. Rich data resources are the basic guarantee of libraries' literature service. Because of their expensive price, foreign electronic resources of every library are not complete. Many libraries have their own distinctive Chinese resources.

With consciousness ascend of independent intellectual property rights, some organizations have begun to set up their own institutional repository (IR) not to sell their knowledge assets such as Ph.D. thesis to commercial data companies cheaply. As a representative, Chinese Academy of Sciences has established 77 institutional repository of subordinate institute. Island services are not only unfavorable for the readers but also not conducive to the development of libraries themselves. The service system of digital library based on cloud computing technology can provide efficient platform to process data and service for libraries which lack technical strength.

So the libraries at the same field can jointly build sharing alliance. Member libraries can carry out digital construction and service of Chinese-foreign resources to provide integrated retrieval and services for readers. The scale advantage of the library service will be helpful to ascend influence of the member libraries. Besides the interlibrary information sharing based on the same platform will be conducive to develop knowledge services and applications. 


\section{Cloud Service Mode of Digital Libraries based on Sharing Alliance}

In the future libraries services will focus on SaaS based on data resources. Several libraries establish the co-construction and sharing system to expand the scope and service mode of information resources. Cloud computing technology is adopted to establish SaaS cloud platform to which member libraries can submit the metadata of their Chinese-foreign resources. Large joint library can provide single sign-on and one-stop service with huge amounts of resources for readers.

\subsection{Cloud Service Model of Digital Library}

The cloud service hierarchy should be built based on the standards system and supported by the operation maintenance and security system. The hierarchy includes data layer, automated management system layer and service layer from bottom to top. The relationship and structure is shown in figure 1.

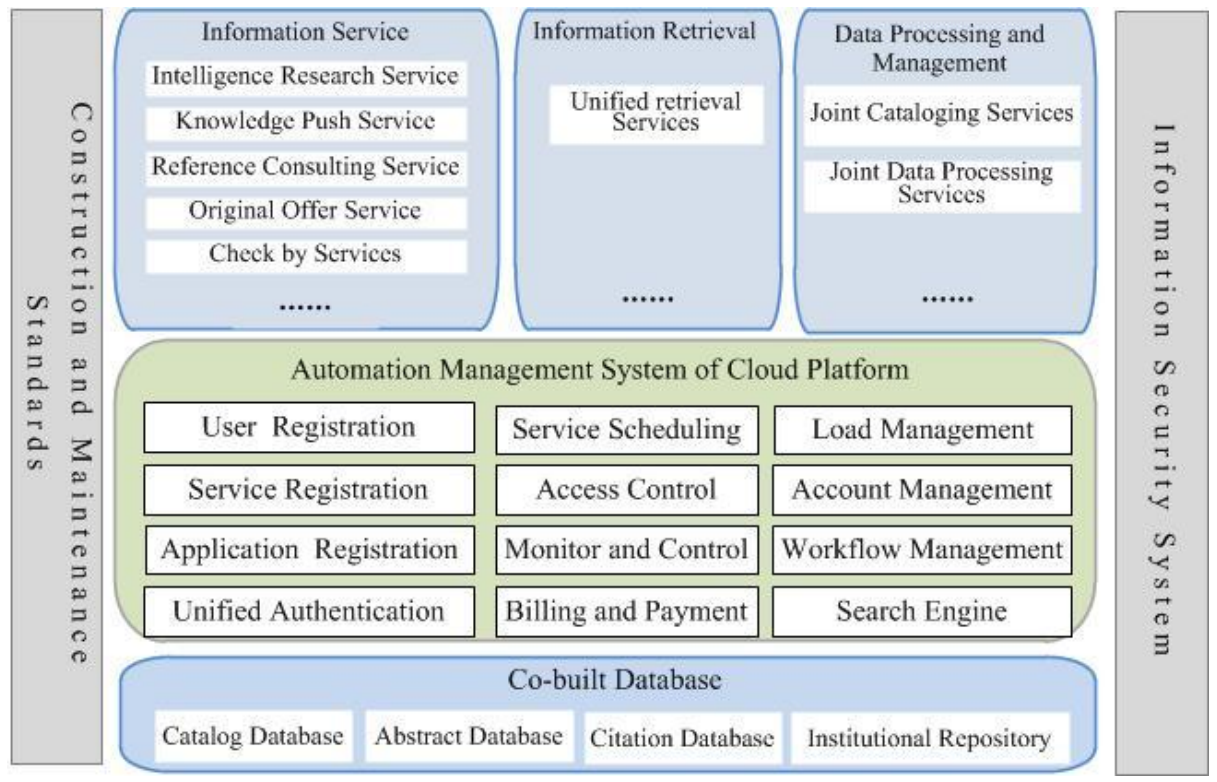

Figure 1 Cloud Service Model of Digital Library 
The data layer is the underlying structure of the three layer service model of cloud services. This layer consists of data resources built by member libraries of shared alliance such as catalog database, abstract database, citation database, institutional repository and so on.

The automated management system layer takes the system management based on data layer. The layer includes a set of middleware service such as user registration, service scheduling, unified authentication, search engine, load management, unified authorization, $\log$ statistics and service register.

The service layer is a set of services based on data layer and the automated management system layer. This layer is a software application model which provides cloud application service through the Internet transmission. The service can be divided into three categories: information service, information retrieval and data processing and management. The cloud services of data processing and management provide a cloud platform based on the unified metadata standard for member libraries. The information cloud service based on co-build data helps member libraries to jointly carry out intelligence research, knowledge push, the original offer, check by services and so on. The information retrieval cloud service provides readers with the retrieval tools to quickly find the resources needed (Chen Chen et .al, 2012).

\subsection{Cloud Service Mode of Digital Libraries based on Sharing Alliance}

The cloud services based on sharing alliance consist of information service, information retrieval and data processing and management. Member libraries can use these cloud services in whole or in part according to need.

\subsubsection{Information Service}

(1) Intelligence Research Service. Intelligence research software based on co-built basic database can be provided to member libraries. By using the software, member libraries can understand their own competitiveness and analysis hot research field so as to provide the basis for future decision-making. 
(2) Knowledge Push Service. Knowledge service software can be provided to member libraries. Thus the readers' access historical data can be analyzed in order to get the interest preference. By being selected, optimized and integrated, information resources can be further developed and pushed to readers. By intelligently filtering and recommending the information, service mode transformation can be promoted from passive service to active service, which the quality of information service can be significantly improved.

(3) Reference Consulting Service. Reference consulting software can be used online. By using the software, librarians can query advisory forms and provide joint consultation among multiple libraries.

(4) Original Offer Service. Original offer software can be used online. Librarians can manage user account, process orders, transfer documents and manage settlement by using the software. Thus querying, acquisition and transmission services of all kinds of literature resources can be provided for researchers and graduate students.

(5) Check by Services. Check by services software can be used online. Librarians can receive and handle the entrusted orders. Query and delivery services facing all kinds of literature resources can be provided for domestic and abroad researchers (Xiaobo Xiao et .al, 2012).

\subsubsection{Information Retrieval}

Unified retrieval function based on sharing alliance resources can be provided. By using the resources search engine, readers can retrieve all abstract information of books, journals, conference proceedings, reports, dissertations, standards and patent documents in cloud service platform to complete one-stop retrieval of printed and digital resources. The retrieval system can be used remotely or be embedded into the web systems of member libraries. 


\subsubsection{Data Processing and Management}

(1) Joint Cataloging Services. Joint cataloging software can be provided for member libraries. By using the software, librarians can process metadata cataloging database of Chinese-foreign journals. Readers can log in the joint cataloging system of cloud services platform to search the resources of all member libraries.

(2) Joint Data Processing Services. Joint data processing software can be provided for member libraries. Librarians can adopt the unified standard to process data so as to provide data support for the retrieval service of Chinese-foreign information resources.

\section{Conclusion}

The wide application of cloud computing technology has brought a revolution to library information service mode. Cloud service has become a growth point of the digital library service innovation. As SaaS, cloud service based on library sharing alliance can significantly improve the efficiency of access to information and the utilization of information resources. In the future libraries should focus on the cloud service mode and play advantages guided by demand.

\section{Acknowledgements}

The work is supported by project of national science and technology library "Research on cloud service model and construction of cloud computing services platform for NSTL (2012XM02)", and the special fund project for Basic Science Research Business Fee, AII "Research on user behavior analysis of website of CAAS"(No. 2014-J-007).

\section{References}

1. OCLC News release. OCLC announces strategy to move library management services to Web scale. 2009-04-23.[2009-05-15].http://www.oclc.org/news/release/200927.htm. 
2. Xiaodong Qiao, Bing Liang, Ying Li. NSTL strategic positioning,the recent advances and future development planning. NSTL Special Issue for 10 Years (Digital Library Forum, http://www.dlf.net.cn), 2010, (10):11-17.

3. Wenqing Wang, Ling Chen. The Model of CALIS Cloud Service Platform for Distributed Digital Libraries. Journal of Academic Libraries, 2009, 4:13-18.

4. Chen Chen, Wenhui Wu. A Research on Cloud Services Pattern Architecture and Innovation for Digital Library Under Cloud Computing Environment. Research on Library Science, 2012, 13:70-74.

5. Xiaobo Xiao, Jing Shao, Huijun Zhang. The third Phase SaaS Platforms and Cloud Services of CALIS. Library and Information Service Online, 2012,3(52):52-56.

6. Yingjun Lu, Yiping Zheng, Zhonghua, Deng. Cloud Service in American Libraries. Library and Information, 2012(3):16-21

7. Daxian Wei, Qiang Xie. Research on the Grass-Roots Service Cloud of the National Digital Library. Journal of the National Library of China, 2012,4(82):40-47 